\title{
Celecoxib for the Treatment of Ankylosing Spondylitis
}

\author{
Jian $\mathrm{Zhu}^{1}$, Cindi Sounthonevat ${ }^{2 *}$, Chris Walker ${ }^{3}$ \\ ${ }^{1}$ Department of Rheumatology, Chinese PLA General Hospital, Beijing, China. \\ ${ }^{2}$ Rutgers Post-Doctoral Fellow at Pfizer, New York, NY, USA. \\ ${ }^{3}$ Pfizer Ltd, Walton Oaks, UK
}

Received: January 3, 2017; Accepted: February 2, 2017; Published: March 6, 2017

*Corresponding author: Cindi Sounthonevat. Rutgers Post-Doctoral Fellow at Pfizer Ltd, New York, NY, USA. Email: Cindi.Sounthonevat@pfizer.com

\begin{abstract}
Ankylosing spondylitis is a debilitating form of chronic inflammatory arthritis which primarily affects the spine. Treatment is based on non-pharmacological therapy, largely exercise, and pharmacological therapy, with non-steroidal anti-inflammatory drugs (NSAIDs) recommended as first-line treatment. One of the most well studied pharmacological treatments for patients with ankylosing spondylitis is the cyclooxygenase-2 selective NSAID celecoxib. This short review highlights the importance of inflammation in the pathology of the disease. Data from randomized, controlled clinical trials of celecoxib in patients with ankylosing spondylitis is reviewed with respect to efficacy and safety. In addition, more recent data from longer-term trials suggest that celecoxib may have disease modifying properties. In addition, more recent data from longer-term trials suggest that celecoxib may have disease modifying properties, with the benefits perhaps being more pronounced in patients with syndesmophytes and elevated inflammation levels indicative of more severe disease. With the benefits perhaps being more pronounced in patients with syndesmophytes and elevated inflammation levels indicative of more severe disease.
\end{abstract}

Keywords: Ankylosing spondylitis; Celecoxib; Disease modification

\section{Introduction}

Ankylosing spondylitis is a form of chronic inflammatory arthritis primarily affecting the spine [1]. The prevalence of ankylosing spondylitis is thought to be between $0 \cdot 1 \%$ and $1 \cdot 4 \%$ [1]. It is a disease of young people, generally presenting around 26 years of age, [2] and being more common in men than women with one study reporting a ratio of males to females of 2.4:1 [3]. Treatment aims to reduce symptoms, maintain flexibility and posture, and retard structural damage $[4,5]$. There is no cure but European and North American treatment guidelines recommend physical therapy/exercise in combination with non-steroidal anti-inflammatory drugs (NSAIDs), including COX-2 selective inhibitors as first-line treatment $[4,5]$.

This publication outlines the key role of inflammation in ankylosing spondylitis and reviews the available data on the safety and efficacy of the COX-2 selective inhibitor celecoxib, one of the more extensively studied NSAID treatments for ankylosing spondylitis. Finally, the potential disease modifying properties of celecoxib are discussed.

\section{Inflammation Is A Key Component Of Ankylosing Spondylitis}

Ankylosing spondylitisis characterized by inflammatory back pain, caused by sacroiliitis and spondylitis, which can lead to bone fusion of sacroiliac joints, vertebral facet joints and inter vertebral discs and a resulting spinal stiffness and loss of mobility [1]. Chronic inflammation likely leads directly to the stiffness and bone fusion, and control of inflammation early in the disease process may prevent ongoing structural damage [6].

\section{Celecoxib Is An Effective Treatment Option For Patients With Ankylosing Spondylitis}

\section{Guidelines}

The European League Against Rheumatism (EULAR) guidelines [5] advise that treatment should be tailored according to the current manifestations of the disease, including status and severity of symptoms. Disease monitoring (on an individual basis) should include patient history, clinical parameters, laboratory tests, and imaging, while non-pharmacological treatment should be based on patient education and regular exercise [5].Ongoing treatment with NSAIDs, including COX-2 selective inhibitors, is recommended as first-line drug treatment with other pharmacological treatments (including analgesics, directed corticosteroid injections, and anti-tumor necrosis factor [TNF] therapy) considered if NSAIDs are ineffective [5]. Surgery may also be considered in more severe, non-responding patients [5].

The American College of Rheumatology (ACR) guidelines [4] are similar, also strongly recommending ongoing treatment with NSAIDs and physical therapy. In the ACR guidelines, antiTNF therapy is strongly recommended in patients who do not respond to NSAIDs as is surgery for more severe patients, while the guidelines strongly recommended against the use of systemic 
glucocorticoids [4].

\section{Clinical data}

There have been five randomized, controlled trials of celecoxib for the treatment of ankylosing spondylitis (Table 1) [7-11]. The trials demonstrated both significantly improved outcomes compared with placebo and non-inferiority compared with non-selective NSAIDs. There were no reported deaths during active treatment; although, in one trial, one patient died following discontinuation of celecoxib due to lack of efficacy but this was considered unrelated to treatment [8]. Reported serious adverse events with celecoxib included severe decreased blood pressure, severe renal calculus, angina pectoris, dyspnoea, sudden hearing loss, deterioration of ankylosing spondylitis, and familial Mediterranean fever but overall incidence was comparable with controls [7-11].

Overall, celecoxib was well tolerated in these trials and was typically associated with numerically fewer gastrointestinal adverse events than the non-selective NSAID comparators [7-11], consistent with the established superior gastrointestinal safety of COX-2 selective inhibitors [12]. There was also no notable difference in cardiovascular adverse events in the trials, although the trials were of limited duration and in relatively young patients (Table 1) [13]. Being significantly younger and with fewer comorbidities than the majority of other patients treated with celecoxib, ankylosing spondylitis patients would likely be at lower risk of gastrointestinal and cardiovascular complications [13]. Nevertheless, currently available data from patients with osteoarthritis and rheumatoid arthritis supports the view that celecoxib is not associated with an increased cardiovascular risk when compared with non-selective NSAIDs such as ibuprofen and naproxen $[14,15]$.

An alternative COX-2 selective inhibitor, etoricoxib, has also been examined in a 52 week randomized, controlled trial [16]. This trial included a 6 week placebo controlled period and a 46week active-comparator controlled period in which etoricoxib at 90 or $120 \mathrm{mg}$ once daily was compared with placebo and naproxen at $500 \mathrm{mg}$ twice daily [16]. At 6 weeks, mean change in pain score was -12.6 with placebo compared with -33.7 with naproxen, and -41.5 and -41.6 with etoricoxib $90 \mathrm{mg}$ and 120 $\mathrm{mg}$, respectively and this improvement was maintained over the 1 year active-comparator phase [16]. The recommended dose of etoricoxib was initially limited to $90 \mathrm{mg} /$ day by health authorities, however recent regulatory activity has led to a reduction in the initial dose of etoricoxib recommended for ankylosing spondylitis in some countries [17]. A starting dose of $60 \mathrm{mg} /$ day is now recommended, with the caveat that some patients may benefit from increasing the dose to $90 \mathrm{mg} / \mathrm{day}$. The labeling further recommends a potential return to $60 \mathrm{mg} /$ day in patients once they are clinically stabilized [18].

\section{Disease Modification In Ankylosing Spondylitis}

There is no cure for ankylosing spondylitis and the use of typical disease-modifying anti-rheumatic drugs (such as sulfasalazine and methotrexate) has not been shown to be effective $[1,5]$. Initially, NSAIDs were considered to only modify the symptoms of ankylosing spondylitis with no effect on the progression of disease. However, long-term follow-up of patients from one randomized controlled trial of celecoxib [7] demonstrated that continuous treatment with celecoxib (for 2 years) resulted in a reduction in radiological progression when compared with patients receiving treatment on demand [19]. This reduction suggested that NSAIDs may have disease modifying properties in addition to the relief of symptoms. A similar reduction in radiological progression was shown in patients with a high intake of NSAIDs over 2 years, with the effect being most pronounced in patients with elevated $C$ reactive protein (CRP) [20]. Increased levels of CRP are associated with more severe disease and treatment with NSAIDs has been shown to reduce levels of CRP [21].

Other acute phase reactants have also been implicated in this process with continuous NSAID treatment leading to a more pronounced slowing of radiographic progression in patients with elevated erythrocyte sedimentation rate (ESR), high Ankylosing spondylitis disease activity score (ASDAS)-CRP, or high ASDAS-

Table 1: Efficacy outcomes in clinical trials of celecoxib in patients with ankylosing spondylitis

\begin{tabular}{|c|c|c|c|c|c|c|c|c|c|}
\hline \multirow[b]{2}{*}{ Study } & \multirow[b]{2}{*}{$\begin{array}{l}\text { Patients } \\
\text { (N) }\end{array}$} & \multirow{2}{*}{$\begin{array}{c}\text { Mean age, } \\
\text { range } \\
\text { (years) }\end{array}$} & \multirow[b]{2}{*}{$\begin{array}{c}\text { Duration } \\
\text { (weeks) }\end{array}$} & \multicolumn{3}{|c|}{ Celecoxib } & \multicolumn{3}{|c|}{ Comparator(s) } \\
\hline & & & & Dose & $\mathbf{N}$ & $\begin{array}{c}\text { Mean change } \\
\text { in pain } \\
\text { intensity }\end{array}$ & Dose & $\mathbf{n}$ & $\begin{array}{c}\text { Mean change } \\
\text { in pain } \\
\text { intensity }\end{array}$ \\
\hline \multirow[t]{2}{*}{ Dougados, 2001 [8] } & \multirow[t]{2}{*}{246} & \multirow[t]{2}{*}{$38-40$} & \multirow[t]{2}{*}{6} & Celecoxib $100 \mathrm{mg}$ qd & 80 & -27 & Ketoprofen $100 \mathrm{mg}$ qd & 90 & -21 \\
\hline & & & & & & & Placebo & 76 & -13 \\
\hline \multirow{2}{*}{ Barkhuizen, 2006 [7] } & \multirow{2}{*}{611} & \multirow{2}{*}{$44-45$} & \multirow{2}{*}{12} & Celecoxib 200 mg qd & 137 & -30.0 & Naproxen 500 mg bid & 157 & -36.3 \\
\hline & & & & Celecoxib $400 \mathrm{mg}$ qd & 161 & -30.4 & Placebo & 156 & -9.9 \\
\hline \multirow{2}{*}{ Sieper, 2008 [10] } & \multirow{2}{*}{458} & \multirow{2}{*}{45} & \multirow{2}{*}{12} & Celecoxib $200 \mathrm{mg}$ qd & 153 & -29.1 & Diclofenac $75 \mathrm{mg}$ bid & 155 & -32.7 \\
\hline & & & & Celecoxib $200 \mathrm{mg}$ bid & 150 & -31.7 & & & \\
\hline Huang, 2014 [9] & 219 & 29 & 6 & Celecoxib 200 mg qd & 111 & -23.8 & Diclofenac 75 mg qd & 108 & -27.1 \\
\hline \multirow{2}{*}{ Walker, 2016 [11] } & \multirow{2}{*}{330} & \multirow{2}{*}{44} & \multirow{2}{*}{12} & Celecoxib $200 \mathrm{mg} q \mathrm{~d}$ & 107 & -25.8 & Diclofenac $50 \mathrm{mg}$ tid & 115 & 28.2 \\
\hline & & & & Celecoxib $400 \mathrm{mg}$ qd & 108 & -30.6 & & & \\
\hline
\end{tabular}


ESR [22]. It is notable that in studies similar to those described above, 2-years continuous treatment with diclofenac [23] did not impact radiographic progression compared with controls, suggesting that disease-modifying effects may be limited to only COX-2 selective inhibitors, or to celecoxib alone.

Inhibition of new bone formation with NSAIDs may be associated with the Wnt signaling pathway which plays an important regulatory role in cartilage cell regeneration and fracture repair processes and interacts with the signally pathway of prostaglandins [24]. A recent genome-wide association analysis showed that the prostaglandin E receptor 4 gene (PTGER4) was associated with susceptibility to, and severity of, ankylosing spondylitis [25] and NSAIDs, in particular COX-2 selective inhibitors, could influence this process.

Syndesmophytes and elevated inflammation levels at baseline are risk factors for radiographic progression in ankylosing spondylitis, and these patients have been shown to benefit more when using NSAIDs continuously [20,22]. This suggests that, in terms of retarding radiographic progression and new bone formation, NSAIDs have the greatest benefit in those patients at higher risk.

\section{Conclusions}

Celecoxib is one of the most well studied NSAID treatments for patients with ankylosing spondylitis with relatively strong evidence for its safety and efficacy. Recent evidence suggests that it may also have disease modifying properties. Patients with a high risk of radiographic progression may benefit from the continued use of celecoxib, even after achieving the significant improvements in clinical symptoms commonly recorded in clinical trials of this class of medicines.

\section{Declarations}

This publication was sponsored by Pfizer. Cindi Sounthonevat and Chris Walker are employees of Pfizer and Chris Walker holds stock options with Pfizer. Jian Zhu reports no conflicts of interest.

Medical writing support was provided by Joshua Fink PhD, of Engage Scientific Solutions, and funded by Pfizer.

\section{References}

1. Braun J, Sieper J. Ankylosing spondylitis. Lancet. 2007;369:13791390.

2. Feldtkeller E, Khan MA, van der Heijde D, van der Linden S, Braun J. Age at disease onset and diagnosis delay in HLA-B27 negative vs. positive patients with ankylosing spondylitis. Rheumatol Int. 2003;23(2):6166.

3. Will R, Edmunds L, Elswood J, Calin A. Is there sexual inequality in ankylosing spondylitis? A study of 498 women and 1202 men. J Rheumatol. 1990;17(12):1649-1652.

4. Ward MM, Deodhar A, Akl EA, Lui A, Ermann J, Gensler LS, et al. American College of Rheumatology/Spondylitis Association of America/Spondyloarthritis Research and Treatment Network 2015 Recommendations for the Treatment of Ankylosing Spondylitis and Nonradiographic Axial Spondyloarthritis. Arthritis Rheumatol. 2016;68(2):282-298. doi: 10.1002/art.39298.

5. Braun J, van den Berg R, Baraliakos X, Boehm H, Burgos-Vargas
R, Collantes-Estevez E, et al. 2010 update of the ASAS/EULAR recommendations for the management of ankylosing spondylitis. Ann Rheum Dis. 2011;70(6):896-904.

6. Schett G, Rudwaleit M. Can we stop progression of ankylosing spondylitis? Best Pract Res Clin Rheumatol. 2010;24(3):363-371. doi: 10.1016/j.berh.2010.01.005.

7. Barkhuizen A, Steinfeld S, Robbins J, West C, Coombs J, Zwillich $\mathrm{S}$. Celecoxib is efficacious and well tolerated in treating signs and symptoms of ankylosing spondylitis. J Rheumatol. 2006;33(9):18051812.

8. Dougados M, Behier JM, Jolchine I, Calin A, van der Heijde D, Olivieri I, et al. Efficacy of celecoxib, a cyclooxygenase 2-specific inhibitor, in the treatment of ankylosing spondylitis: a six-week controlled study with comparison against placebo and against a conventional nonsteroidal antiinflammatory drug. Arthritis Rheum. 2001;44(1):180-185.

9. Huang F, Gu J, Liu Y, Zhu P, Zheng Y, Fu J, et al. Efficacy and safety of celecoxib in chinese patients with ankylosing spondylitis: a 6-week randomized, double-blinded study with 6-week open-label extension treatment. Curr Ther Res Clin Exp. 2014;76:126-133. doi: 10.1016/j. curtheres.2014.08.002.

10. Sieper J, Klopsch T, Richter M, Kapelle A, Rudwaleit M, Schwank S, et al. Comparison of two different dosages of celecoxib with diclofenac for the treatment of active ankylosing spondylitis: results of a 12week randomised, double-blind, controlled study. Ann Rheum Dis. 2008;67(3):323-329.

11.Walker C, Essex MN, Li C, Park PW. Celecoxib versus diclofenac for the treatment of ankylosing spondylitis: 12-week randomized study in Norwegian patients. J Int Med Res. 2016;44(3):483-495.

12. Moore RA, Derry S, Phillips CJ, McQuay HJ. Nonsteroidal antiinflammatory drugs (NSAIDs), cyxlooxygenase-2 selective inhibitors (coxibs) and gastrointestinal harm: review of clinical trials and clinical practice. BMC Musculoskelet Disord. 2006; 7:79.

13. Poddubnyy DA, Song IH, Sieper J. The safety of celecoxib in ankylosing spondylitis treatment. Expert Opin Drug Saf. 2008;7(4):401-409. doi: 10.1517/14740338.7.4.401.

14. Bhala N, Emberson J, Merhi A, Abramson S, Arber N, Baron JA, et al. Vascular and upper gastrointestinal effects of non-steroidal antiinflammatory drugs: meta-analyses of individual participant data from randomised trials. Lancet. 2013;382(9894):769-779.doi: 10.1016/S0140-6736(13)60900-9.

15. Nissen SE, Yeomans ND, Solomon DH, Lüscher TF, Libby P, Husni $\mathrm{ME}$, et al. Cardiovascular Safety of Celecoxib, Naproxen, or Ibuprofen for Arthritis. N Engl J Med. 2016;375(26):2516-2529. doi: 10.1056/ NEJMoa1611593.

16.van der Heijde D, Baraf HS, Ramos-Remus C, Calin A, Weaver AL, Schiff $M$, et al. Evaluation of the efficacy of etoricoxib in ankylosing spondylitis: results of a fifty-two-week, randomized, controlled study. Arthritis Rheum. 2005;52(4):1205-1215.

17. Medicines and Healthcare products Regulatory Agency. Drug Safety Update. 2016;10(3). Accessed 12 December, 2016.

18. Etoricoxib Summary of Product Characteristics. Available at: http:// www.mhra.gov.uk/home/groups/spcpil/documents/spcpil/ con1478239858936.pdf Accessed 12 December, 2016.

19. Wanders A, Heijde D, Landewe R, Behier JM, Calin A, Olivieri I, et al. Nonsteroidal antiinflammatory drugs reduce radiographic progression in patients with ankylosing spondylitis: a randomized clinical trial. Arthritis Rheum. 2005;52(6):1756-1765. 
20.Poddubnyy D, Rudwaleit M, Haibel H, Listing J, Marker-Hermann E, Zeidler $\mathrm{H}$, et al. Effect of non-steroidal anti-inflammatory drugs on radiographic spinal progression in patients with axial spondyloarthritis: results from the German Spondyloarthritis Inception Cohort. Ann Rheum Dis. 2012;71(10):1616-1622.

21.Benhamou M, Gossec L, Dougados M. Clinical relevance of C-reactive protein in ankylosing spondylitis and evaluation of the NSAIDs/ coxibs' treatment effect on C-reactive protein. Rheumatology (Oxford). 2010;49(3):536-541.

22. Kroon F, Landewe R, Dougados M, van der Heijde D. Continuous NSAID use reverts the effects of inflammation on radiographic progression in patients with ankylosing spondylitis. Ann Rheum Dis. 2012;11(10):1623-1629. doi: 10.1136/annrheumdis-2012-201370.
23. Sieper J, Listing J, Poddubnyy D, Song IH, Hermann KG, Callhoff J, et al. Effect of continuous versus on-demand treatment of ankylosing spondylitis with diclofenac over 2 years on radiographic progression of the spine: results from a randomised multicentre trial (ENRADAS). Ann Rheum Dis. 2016;75:1438-1443.

24. Wendling D, Claudepierre P. New bone formation in axial spondyloarthritis. Joint Bone Spine. 2013;80(5):454-458.

25. Chai W, Lian Z, Chen C, Liu J, Shi LL, Wang Y. JARID1A, JMY, and PTGER4 polymorphisms are related to ankylosing spondylitis in Chinese Han patients: a case-control study. PLoS One. 2013;8(9):e74794. doi: 10.1371/journal.pone.0074794. 